University of Louisville

ThinkIR: The University of Louisville's Institutional Repository

8-2014

\title{
Cholinergic inhibition of lipopolysaccharide induced matrix metalloproteinase in immune cells.
}

Harrison Black,

University of Louisville

Follow this and additional works at: https://ir.library.louisville.edu/etd

Part of the Oral Biology and Oral Pathology Commons

\section{Recommended Citation}

Black, Harrison, "Cholinergic inhibition of lipopolysaccharide induced matrix metalloproteinase in immune cells." (2014). Electronic Theses and Dissertations. Paper 115.

https://doi.org/10.18297/etd/115

This Master's Thesis is brought to you for free and open access by ThinkIR: The University of Louisville's Institutional Repository. It has been accepted for inclusion in Electronic Theses and Dissertations by an authorized administrator of ThinkIR: The University of Louisville's Institutional Repository. This title appears here courtesy of the author, who has retained all other copyrights. For more information, please contact thinkir@louisville.edu. 


\title{
CHOLINERGIC INHIBITION OF LIPOPOLYSACCHARIDE INDUCED MATRIX METALLOPROTEINASE IN IMMUNE CELLS
}

\author{
By \\ Harrison Black \\ B.S., D.M.D, University of Louisville, 2014

\begin{abstract}
A Thesis
Submitted to the Faculty of the School of Dentistry of the University of Louisville In Partial Fulfillment of the Requirement for the Degree of
\end{abstract} \\ Master of Science \\ Department of Oral Health and Rehabilitation \\ University of Louisville, School of Dentistry \\ Louisville, KY
}

August 2014 



\section{CHOLINERGIC INHIBITION OF LIPOPOLYSACCHARIDE INDUCED MATRIX METALLOPROTEINASE IN IMMUNE CELLS.}

\section{By}

Harrison Black

B.S., D.M.D, University of Louisville, 2014

A Thesis approved on

June 26, 2014

By the following ThesisCommittee:

David Scott (Thesis Director)

Huizhi Wang

Jan Potempa 


\section{ACKNOWLEDGMENTS}

I would like to first thank God for the opportunity to pursue knowledge and to explore new things. My journey in research has been amazing. Starting at Truman State where I participated in the Summer Research Education program with Dr. Russell Baughman. I would like to thank Dr. Baughman for establishing my research background. I am so grateful for your guidance all four years of undergraduate studies.

As I moved from undergraduate studies in to dental school I continued in research I would like to thank Dr. Lamont for giving me the chance to work in his lab and get introduced to research at the next level. Dr. Scott I really appreciate everything you have done for me in my research career. Thanks for instruction and encouraging me to present at different conferences. Thanks for helping me with the Cancer Education Program it was a great experience to be a part of a program with clinicians and researchers from different aspects of research. The Cancer Education Program deserves many thanks as well for selecting me and giving me funding so I could continue my research pursuits. I would like to thank everyone in the Scott who helped me as I achieved my goals.

Finally I would like to thank my family for their support. I had many summers where I would be working in the lab and you stuck by my side with love and support. Thanks so much to my mother for her support. Thanks so much to my wife Erin for reading everything I wrote and pushing me when I was losing passion. Thanks Chloe for being you. Thanks Everyone! 


\begin{abstract}
CHOLINERGIC INHIBITION OF LIPOPOLYSACCHARIDE INDUCED MATRIX METALLOPROTEINASE IN IMMUNE CELLS
\end{abstract}

By

Harrison Black

June 26, 2014

Background: Matrix metalloproteinase (MMPs) are proteins that have a unique role in immunity, tissue remodeling, and tumorigenesis. MMPs can break down extracellular components, release bioactive molecules, and act on pro-inflammatory cytokines, chemokines and other proteins to regulate varied aspects of inflammation and immunity. Nicotine (3-(1-methyl-2-pyrrolidinyl) pyridine), a key toxic component of tobacco, is thought to dysregulate matrix metalloproteinase secretion in immune cells. Aim: Examine the effect of nicotine on MMP9 secretion and activity in primary monocytes. Methods: Primary monocytes were stimulated with LPS $(1 \mu \mathrm{g} / \mathrm{ml})$ and Nicotine (100 $\mathrm{ng} / \mathrm{ml}$ ) and MMP9 secretion were studied. Gel zymography and ELISA techniques were used to study the secretion of MMP9 due to nicotine. Furthermore siRNA techniques were used to understand the role of the $\alpha 7$ nicotinic acetylcholine receptor ( $\alpha 7 \mathrm{nAChR})$ characterize the MMP production. Conclusion: Nicotine decreased the MMP9 activity and secretion in primary monocytes. The $\alpha 7 \mathrm{nAChR}$ receptor has an important role in the secretion and activity of MMP9 production in primary monocytes. 


\section{TABLE OF CONTENTS}

ACKNOWLEDGEMENTS ..........................................ii

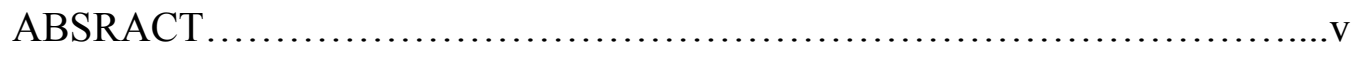

LIST OF FIGURES .................................................vii

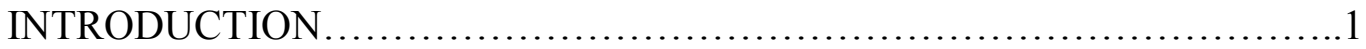

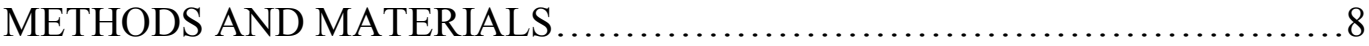

RESULTS..........................................................11

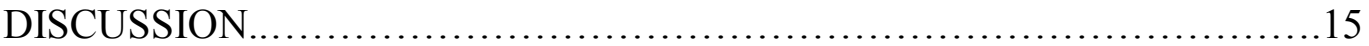

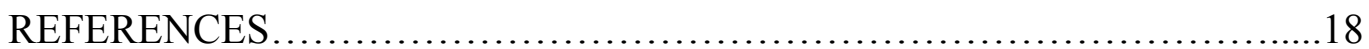

CURRICULUM VITAE...............................................23 


\section{LIST OF FIGURES}

Introduction

Figure 1: $\quad$ Tobacco smoking and disease..................................

Figure 2: $\quad \alpha 7 \mathrm{nAChR}$ dependent anti-inflammatory pathway................4

Results

Figure 3: $\quad$ Nicotine suppresses MMP9 secretion.........................9

Figure 4: Nicotine suppresses MMP9 secretion in an $\alpha 7 \mathrm{nAChR}$ dependent manner (pharmaceutical inhibition............................9

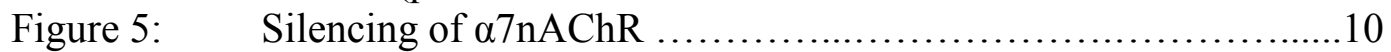

Figure 6: Nicotine suppresses MMP9 secretion in an $\alpha 7 \mathrm{nAChR}$ dependent manner (gene silencing) ................................ 10

Figure 7: $\quad$ Nicotine suppresses MMP9 activity in an $\alpha 7 \mathrm{nAChR}$ dependent manner (gene silencing)..................................11 


\section{INTRODUCTION}

\section{Tobacco and Disease}

The World Health Organization in a recent statement reported that tobacco is the cause of death for nearly 6 million people per year and unless action is taken the annual

death toll could rise to more than eight million by 2030 ("WHO Media Center," 2014) The history of tobacco related research started with correlating the use of tobacco with disease through epidemiology, then there was a shift in perspective and prevention of tobacco use was pursued and recently more studies have begun to pursue the molecular correlation to tobacco as an environmental factor of disease. (Wang and Scott 2005) The most recent United States Surgeon General report 2010. "How Tobacco Smoke Causes Disease." put emphasis on the biologic mechanisms that make up the pathogenicity of tobacco smoke and stressed the importance of finding a biological association with previous epidemiological studies. Understanding the molecular basis of tobacco and disease leading to various inflammatory process is innovative and could possibly lead to therapies that can help prevent disease due to tobacco use.

Past epidemiologic studies have shown strong correlation between tobacco use and chronic disease (Figure 1.) including heart disease, cancer and microbial infections such as bacterial meningitis, periodontitis and post-surgical infections. (Centers for Disease Control and Prevention 2010; Bagaitkar 2008) 


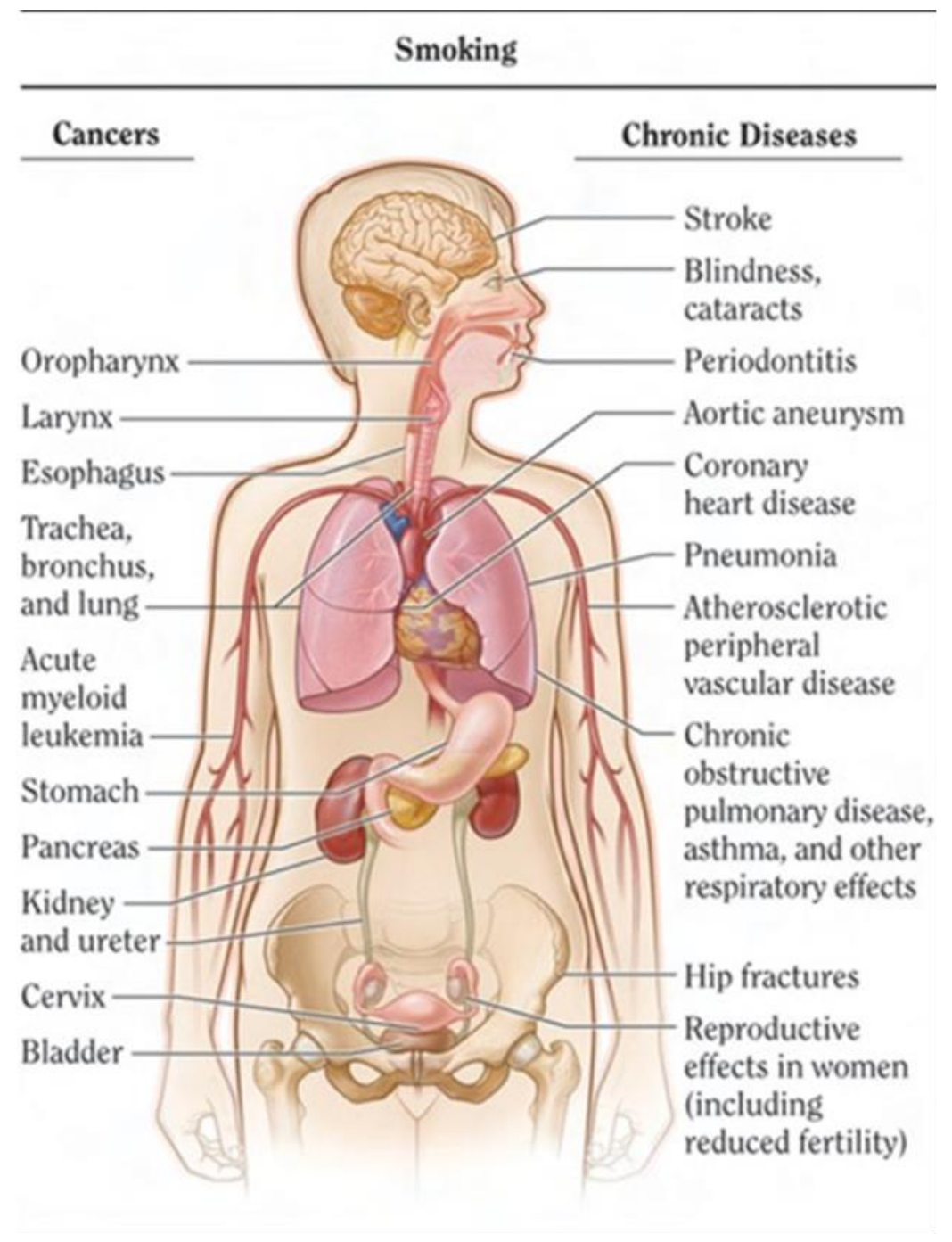

Figure 1. The health consequences causally linked to smoking. USDHHS 2004, 2006.

These clinical correlations are very important because they give the base line to the biological inquiry. For example, cigarette smokers can have a disruption in endothelial cells which can propagate into vascular diseases or accelerate existing vascular disease. Mechanisms like decreases in nitrous oxide generation or bioavailability and increase in oxidative stress by free radicals are being explored as potential pathways for cigarette smoking mediated cardiovascular dysfunction. (Kugiyama et al., 1996) In addition, general mechanisms have been proposed for smoker's susceptibility to 
pathogenic or opportunistic bacteria. The mechanisms include (i) tobacco-induced physiological and structural changes in human smokers, (ii) tobacco-induced increase in bacterial virulence and (iii) tobacco-induced dysregulation of immune function. (Wang and Scott 2005) These studies bring insight to mechanisms in tobacco induced physiological changes by hindering the mucociliary clearance and the dysregulation of immune system. Overall, the mechanisms behind tobacco's ability to cause disease needs to be further study so that a better perspective of disease progression can be known.

Periodontal disease is chronic progressive disease that affects an estimated $22 \%$ of US adults with mild forms of the disease and $13 \%$ with moderate to severe disease.(Albandar et al., 1999) Periodontal disease is described as dental plaque, a bacterial biofilm, accumulation on teeth near the gingiva causing damage to the gingiva, alveolar bone and periodontal ligaments. (Highfield 2009) Clinical symptoms of periodontitis are red, swollen gums that may bleed easily. Periodontitis progression (Figure 2.) results in the loss of alveolar bone and connective tissue around the tooth which is a major cause of tooth loss in adults. Periodontitis has progressive forms starting with gingivitis, mild to moderate, and severe periodontitis. They are categorized by the clinical attachment loss which is the loss of connective tissue and alveolar bone. The biology behind periodontal disease are pathogenic microorganisms which include Porphyrmonas gingivalis, Tannerella forsythesis, and Treponema denticola. (Holt et al., 2005) Each of these organisms play a unique role in the disease process of periodontitis because each microorganism has specific virulence factors that change the environment of the bacterial biofilm. For example $P$. gingivalis In addition to pathogenic organisms, 
genetic and environmental factors such as tobacco contribute to the periodontitis disease process. (Reviewed. Pihlstrom et al., 2005)

A.

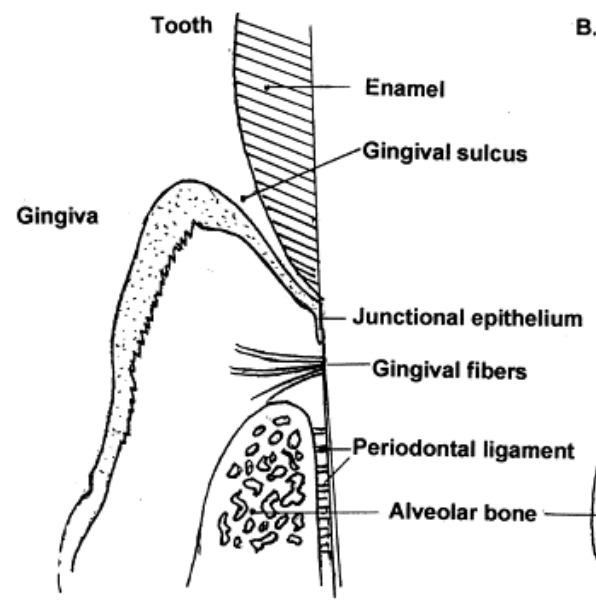

B.

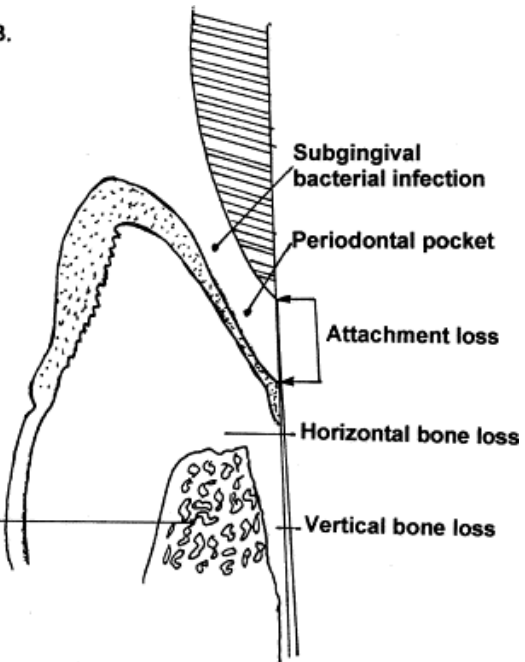

Figure 2. Periodontal progression as reviewed Baker P.J. 2000

A strong correlation is seen between tobacco smokers and periodontal disease. Tobacco users have a 5 to 20 fold risk of developing periodontitis that a non-smoker. (Bergström 2004) Research has shown that smokers have an increase in susceptibility to periodontal disease but a suppression of gingival inflammation and pro-inflammatory cytokines. (Scott and Singer, 2004; Palmer et al., 2005 and Johnson and Guthmiller. 2007) This interesting perspective created a "clinical conundrum" about periodontal disease because smoking hides the signs of the infection from the dental professional during clinical examination. To further understand the "clinical conundrum" study has been lead to review evidence that tobacco smoke may cause (i) acute periodontal vasoconstriction, (ii) inhibit periodontal angiogenesis in response to inflammatory mediators, and/or (iii) suppress the production of pro-inflammatory mediators. (Scott and Singer 2004) 
Tobacco contains approximately 4500 constituents that are harmful, toxic and potentially carcinogenic. Nicotine (3-(1-methyl-2-pyrrolidinyl) pyridine) is a constituent of tobacco known to be the addictive substance (Storr et al., 2004) and plays a unique role in tobacco use. Nicotine interacts with nicotinic acetylcholine receptors which initially were thought to just be located in the brain but research has shown that the receptors are located on additional cells specifically immune cells. (Arias et al., 2009) There are currently nine nicotinic acetylcholine receptor subunits. The $\alpha 7 \mathrm{nAChR}$ receptor is important because it may have the potential to involve the cholinergic antiinflammatory pathway on innate immune cells. Inflammation is a balance between systems of the pro-inflammatory system and the anti-inflammatory. Regulation of prolonged inflammation is critical to prevent chronic inflammatory diseases such as periodontal disease. Our study will explore periodontal disease mechanisms to further the body of knowledge of tobacco and disease.

Matrix metalloproteinase (MMPs) are a family of approximately 28 secreted and membrane-bound zinc-endopeptidases involved in angiogenesis and tissue remodeling. Recent studies show they have a unique role in regulating the release or activation of chemokines, cytokines, growth factors, and other bioactive molecules thus participating in physiological processes such as innate and adaptive immunity, inflammation, angiogenesis, bone remodeling and neurite growth.(Loffek et al., 2011) The activity of MMPs is tightly regulated Matrix metalloproteinase at four different levels which are gene expression, compartmentalization, pro-enzyme activation and inhibition of proteolysis by tissue inhibitors of matrix metalloproteinase (TIMPs). When MMPs are 
deregulated in knockout mice the mice show susceptibility to skin cancer, impaired wound healing in skin, altered inflammatory response in wounds, delay of neutrophil infiltration and impaired primary angiogenesis. (Page-McCaw et al., 2007) For example, MMP-9 has role in the migration and proliferation of endothelial cells (neo-angiogenesis) by releasing vascular endothelial growth factor (VEGF) and tumor necrosis factor (TNF)$\alpha$ from the ECM. (Brinckerhoff and Matrisian 2002) If neo-angiogenesis is disturbed it has implication in poor wound healing. (Galis et al., 2002)

Matrix metalloproteinase also have been a therapeutic target in periodontal disease with the application of sub-antimicrobial doses of tetracycline because MMP increase has been linked with incidence of the periodontal disease. (Gu et al., 2011) Periodontal disease in its chronic form is the progressive break down of connective tissue and bone and Matrix Metalloproteinase have a direct effect on the ECM and the breakdown of tissue. A general mechanism can be described as endotoxin (lipopolysaccharide LPS) from the gram-negative periodontal pathogens, induce a local accumulation of mononuclear cells and increase pro-inflammatory cytokines and MMPs which destruct the periodontal tissues.

Continuing with the general periodontal disease mechanism; periodontal pathogens have LPS-like constituents that immune cells can recognize with their Tolllike receptors that are located on the cell surface then stimulate the inflammatory response, which is observed in the increase of pro-inflammatory cytokines. Immune cells which have been exposed to nicotine and nicotinic byproducts have an altered inflammatory response. (Bagaitkar et al., 2012) It is proposed that nicotine 
inappropriately engages the immune cell's $\alpha 7 \mathrm{nAChR}$ receptor to regulate the cholinergic anti-inflammatory pathway which is used to control the immune overexpression and therefore limits the inflammatory response. Cytokines and chemokines in the inflammatory response have a unique relationship with the ECM and can be somewhat regulated through bioavailability in the ECM so matrix metalloproteinase have a unique role in innate immunity. We have recently seen that Matrix Metalloproteinase secretion was disrupted by nicotine exposure. (Xu et al., 2008) Current research is limited on the novel approach to MMP9 regulation with in the immune system. Therefore, we will assess if matrix metalloproteinase 9 is effected by the cholinergic inhibition of the antiinflammatory pathway by nicotine when immune cells are exposed to LPS. The role of a7nACh receptor in MMP9 production will be studied through pharmacological inhibition and siRNA silencing techniques. Matrix metalloproteinase secretion will be monitored by enzyme linked immunosorbent assay and gel zymography. Our primary model of this pathway is described by Figure 3 . 


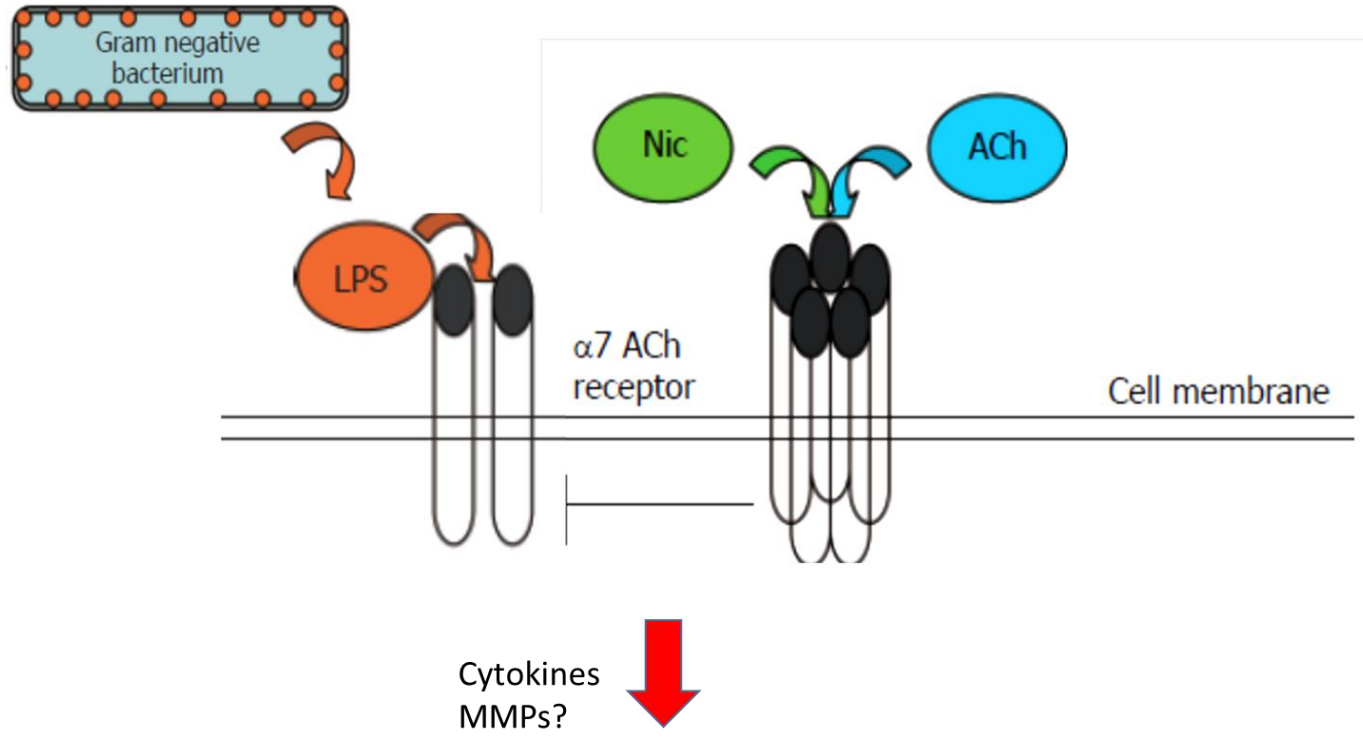

Figure 3. $\alpha 7 \mathrm{nAChR}$ dependent anti-inflammatory pathway 


\section{MATERIALS AND METHODS}

\section{Materials}

Ultra-pure LPS from Escherichia coli 0111:B4 were purchased from Invivogen. (-)-Nicotine was purchased from Sigma-Aldrich Co., St. Louis, MO. $\alpha$-Bungarotoxin was purchased from Tocris Bioscience. $\alpha 7 \mathrm{nAChR}$ antibody (H-302), $\alpha 7 \mathrm{nAChR}$ siRNA (h) and scrambled control siRNA were purchased from Santa Cruz Biotechnology, Inc, Dallas, Tx. All other Abs were obtained from Cell Signaling Technology. Cytokine ELISA kits were purchased from eBioscience.

\section{Cell preparation}

PBMCs were obtained from the venous blood of healthy donors as per protocols approved by the University of Louisville, Institutional Review Board, and Human Subjects Protection Program. Monocytes were isolated by negative selection using the human monocyte isolation kit II from Miltenyi Biotec. The purity of monocytes was routinely $>90 \%$, as determined by flow cytometry using an FITC-labeled anti-CD14 Ab. Monocyte cells were cultured in RPMI 1640 medium supplemented with 10\% FBS, $1 \mathrm{mM}$ sodium pyruvate, $2 \mathrm{mM}$ L-glutamine (Wang, Garcia et al. 2008). 


\section{Gelatin zymography}

The conditioned growth media were mixed with $4 \mathrm{x}$ non-reducing sample buffer and resolved at $120 \mathrm{~V}$ in $7.5 \%$ sodium dodecylsulphate-polyacrylamide gel electrophoresis (SDS-PAGE) gels copolymerized with $1 \mathrm{mg} / \mathrm{ml}$ gelatin. The gels were then washed with $2.5 \%$ Triton $\mathrm{X}-100$ for three 20 min cycles. The gels were then incubated in fresh zymogram buffer containing $50 \mathrm{~mm}$ Tris ( $\mathrm{pH} 7.5), 3 \mathrm{mM} \mathrm{NaN}_{3}$, $5 \mathrm{mM} \mathrm{CaCl}_{2}$ and $1 \mu \mathrm{M} \mathrm{ZnCl}_{2}$ at $37^{\circ} \mathrm{C}$ overnight and were stained with Coomassie blue to visualize the proteolytic bands.

\section{Transfection, cytokine detection, and Western blot}

Transfection of human monocytes were carried out by electroporation using a 4D Nucleofector device (Lonza) according to the manufacturer's protocols. Briefly, purified $1 \times 10^{7}$ monocytes were resuspended in $100 \mu$ l Nucleofector solution (Human Monocytes Nucleofector kit; Lonza) and $6 \mu \mathrm{g}$ siRNA duplexes for each $\alpha 7 \mathrm{nAChR}$ nicotinic receptor and scrambled control siRNA duplex. Immediately after electroporation, $1 \mathrm{ml}$ pre warmed RPMI growth media containing $10 \%$ FBS were added to cells that were then transferred into 96 well plate. At $48 \mathrm{~h}$ post transfection, cells were exposed to LPS (1 $\mu \mathrm{g} / \mathrm{ml}$ ) with or without Nicotine. Cell lysates were prepared using RIPA buffer. For siRNA studies, transfected cells were stimulated with LPS $(1 \mu \mathrm{g} / \mathrm{ml})$ and Nicotine $(100$ $\mathrm{ng} / \mathrm{ml}$ ), $3 \mathrm{~d}$ post transfection, and cell-free supernatants were assayed for cytokine levels by ELISA (eBioscience) at $18 \mathrm{~h}$. 


\section{Western blot}

An equal amount of total protein from primary monocyte resolved in $10 \%$ SDSPAGE gels at $120 \mathrm{~V}$. The proteins on the gels were transferred to nitrocellulose membrane at $0.3 \mathrm{~A}$ for $90 \mathrm{~min}$ using transfer buffer $(25 \mathrm{~mm}$ Tris- $\mathrm{HCl}$ ( $\mathrm{pH} 8.3)$, $192 \mathrm{~mm}$ glycine and 10\% methanol). The membranes were then incubated in $3 \%$ milk in tris-buffered solution with $0.1 \%$ Tween-20 (TBST, $\mathrm{pH}$ 7.4) for $1 \mathrm{~h}$ to block nonspecific binding. The membranes were then incubated with primary antibodies at $4{ }^{\circ} \mathrm{C}$ overnight. Antibodies used in this study were anti- $\alpha 7 \mathrm{nAChR}$, anti-GSK3b, anti-MMP-9, and $\beta$ actin. The membranes were then washed three times with TBST and incubated with horseradish peroxidase-conjugated secondary antibodies for $1 \mathrm{~h}$ at room temperature. Chemiluminescence was detected by an ECL-Plus kit (Thermo Scientific, Pittsburgh, PA) and the protein bands were visualized using ImageQuant LAS 4010 (GE Heathcare, Pittsburgh, PA). Densitometric analysis of protein band intensity was performed using the GelQuantNET software (biochemlabsolutions.com) and normalized with the loading control.

\section{Statistical analysis}

All data are presented as means \pm SEM. Comparison between groups was made using one-way ANOVA with the Fisher multiple comparison test. A probability value of $p<0.05$ was considered statistically significant. All cell culture experiments were performed in triplicate on at least three separate occasions. 


\section{RESULTS}

\section{Nicotine Suppresses LPS induced secretion of MMP9}

Primary monocytes were stimulated with LPS $(1 \mu \mathrm{g} / \mathrm{ml})$ and Nicotine $(100 \mathrm{ng} / \mathrm{ml})$ and MMP9 secretion were studied by ELISA. As shown in figure 3. LPS leads to significant increase in MMP9 secretion which is blocked by $100 \mathrm{ng} / \mathrm{ml}$ nicotine. Nicotine alon had no significant effect on MMP9 secretion as compared to vehicle.

$$
\begin{aligned}
& \overline{\bar{E}} \\
& \text { อ } \\
& \text { g } \\
& \text { ¿ }
\end{aligned}
$$

LPS $(1 \mu \mathrm{g}$ Nicotine ( Figure 4. Nicotine suppresses MMP9 secretion. 


\section{$\underline{\text { Nicotine suppresses MMP9 secretion } \alpha 7 n A C h R \text { dependent manner }}$}

To understand the role of $\alpha 7 \mathrm{nAChR}$ in monocyte secretion of MMP9, the cells were pretreated with $\alpha$-bungarotoxin (BTX). $\alpha$-bungarotoxin known to bind irreversibly to $\alpha 7 \mathrm{nAChR}$ thereby preventing nicotine to bind to it. As shown in figure 4 , BTX had no effect on LPS induced secretion of MMP9 as studied by ELISA but when LPS was added to nicotine treated monocytes, nicotine failed to block the effect of LPS on MMP9 secretion suggesting the role of $\alpha 7 \mathrm{nAChR}$ in secretion of MMP9. Furthermore, to establish the role of $\alpha 7 \mathrm{nAChR}$ in secretion of MMP9 in monocytic cells, we used knockdown approach using siRNA techniques. First, we established that we could significantly knock down the expression of $\alpha 7 \mathrm{nAChR}$ using western blot techniques (Figure 5). Thereafter, we studied the effect of nicotine on LPS induced secretion of MMP9 in monocytic cells. In the same siRNA treated cells nicotine has lost it ability to block the LPS induced secretion of MMP9 in the monocytic cells as quantified by ELISA (Figure

$6)$.

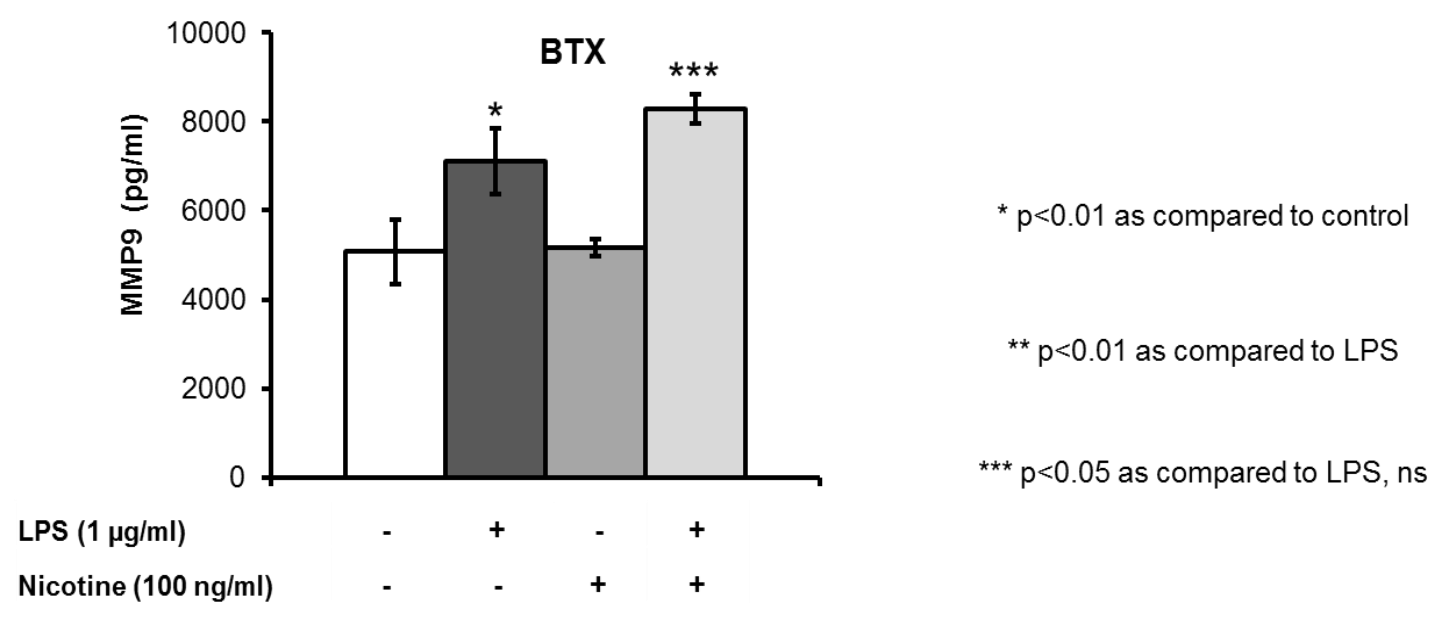


Figure 5. Nicotine suppresses MMP9 secretion $\alpha 7 \mathrm{nAChR}$ dependent manner (pharmaceutical inhibition)

\section{Nicotine suppresses MMP9 secretion $\alpha 7 \mathrm{nAChR}$ dependent manner}
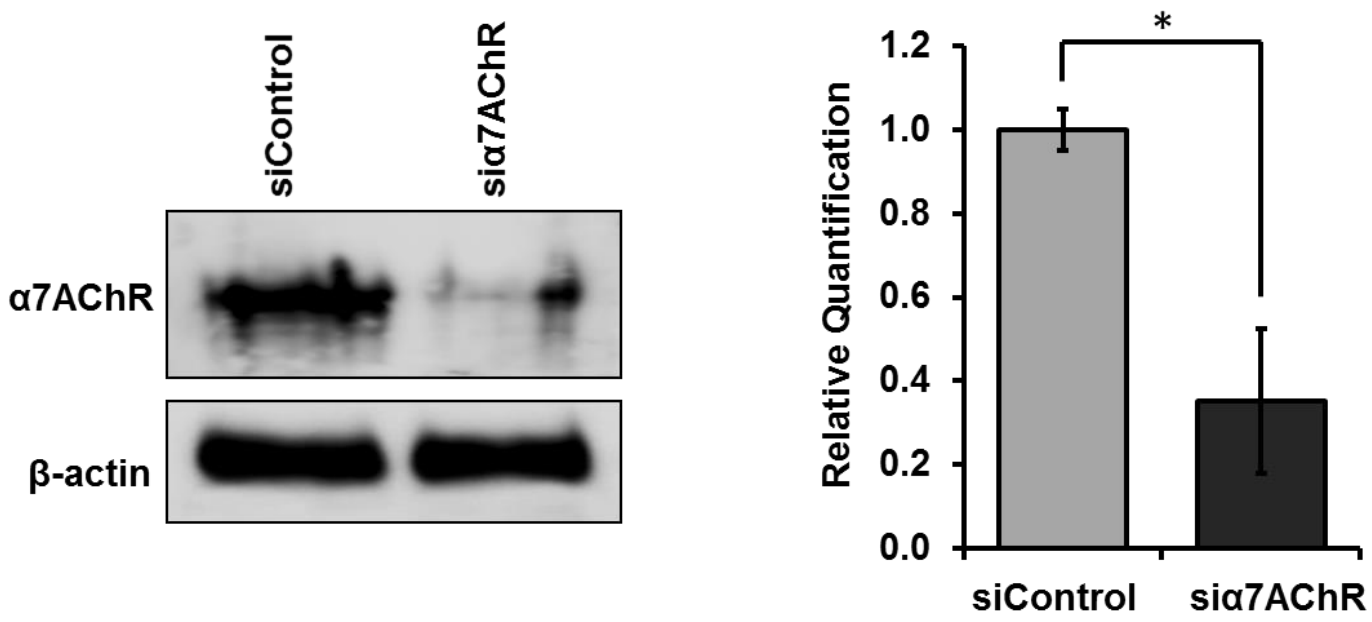

${ }^{*} \mathrm{P}<0.05$

Figure 6. Silencing of $\alpha 7 \mathrm{nAChR}$ 


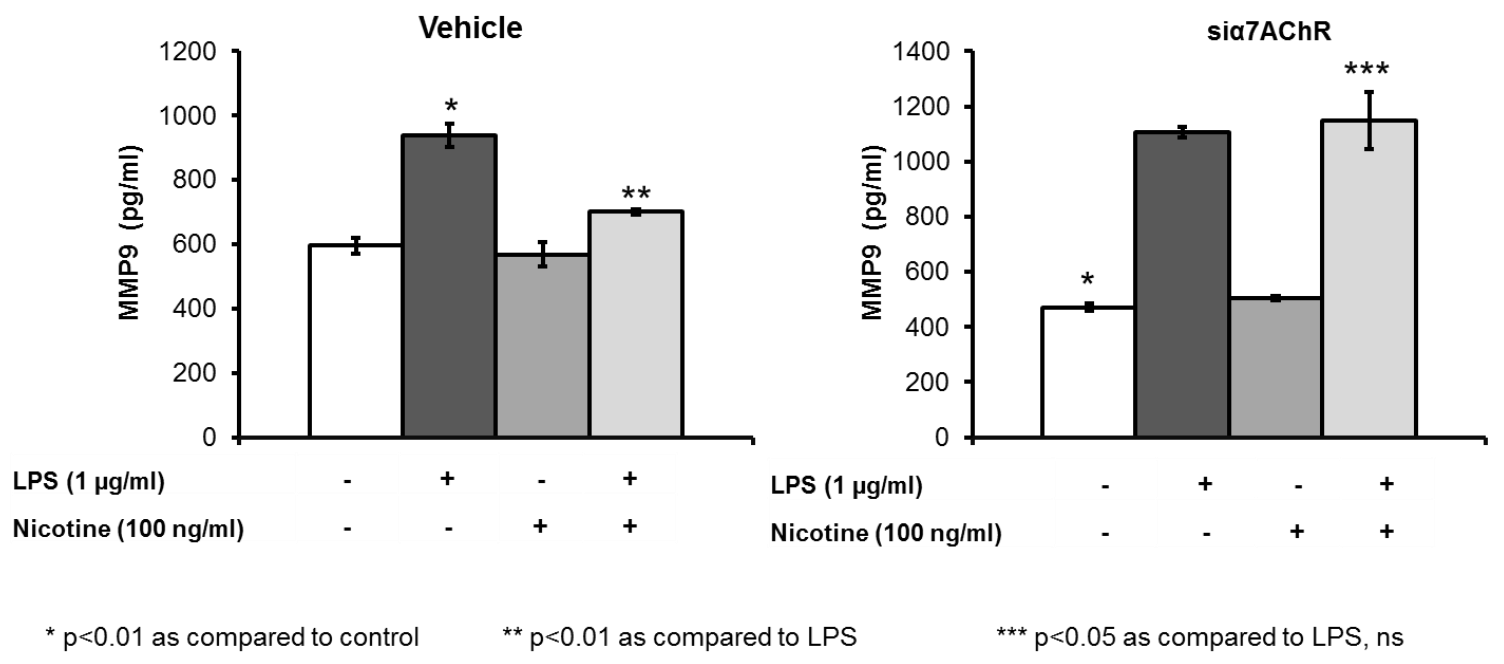

Figure 7. Nicotine suppresses MMP9 secretion $\alpha 7 \mathrm{nAChR}$ dependent manner (gene silencing) 


\section{Nicotine blocks the LPS induced secretion of MMP9 as studied by zymogram}

We studied the effect of nicotine on LPS induced secretion of MMP9 using $0.1 \%$ gelatin gel. As evident from the figure 7, the nicotine lead to decrease in active MMP9 activity in LPS induced MMP9 secretion in the scrambled control siRNA treated monocytic cells but the blocking effect of nicotine on LPS induced secretion of active MMP9 was significantly reduced in the $\alpha 7 \mathrm{nAChR}$ siRNA treated monocytic cells.

Nicot

Figure 8. Nicotine suppresses MMP9 secretion $\alpha 7 \mathrm{nAChR}$ dependent manner (gene silencing) 


\section{DISCUSSION}

Matrix metalloproteinases are involved in multiple disease process such as impaired wound healing, bone-development defects, and chronic periodontitis. (Vu 1998) We are interested in how matrix metalloproteinase regulation relates to periodontal disease. Current research shows correlation between oral fluid and MMP9 as a potential biomarker for periodontal disease. (Loo et al., 2011; Keles et al., 2006) Periodotitis has a close relationship with environmental factor of smoking. Smoking suppresses clinical inflammation. In addition, smoking suppresses cytokines. Nicotine reduces proinflammmatory cytokine, which promotes survival of periodontal pathogens that encourage disease progression.

Current research is limited on the novel approach to MMP9 regulation with in the immune system. Here we show that Matrix Metalloproteinase are suppressed as well and these results are consistent with decreased inflammation/increased disease in smokers. Decreased matrix metalloproteinase secretion and activity may help to protect bacteria because matrix metalloproteinases release cytokines and chemokines with their proteolytic cleavage. Matrix metalloproteinases are involved with angiogenesis and wound healing and a suppression of MMP may cause delay in the healing process. Nicotine ability to engage the anti-inflammatory pathway and interfere with matrix metalloproteinase is novel as well. The anti-inflammatory pathway has been studied in its 
role in other inflammatory cytokines but to perhaps matrix metalloproteinase 9 into its mechanism of action is novel because matrix metalloproteinase is a proteinase and not a cytokine or chemokine. Matrix metalloproteinases have the ability to structurally change the extracellular matrix to allow for the availablilty of cytokines and chemokines which further express the inflammatory response that it is novel that nicotine could possibly be interferning with the inflammatory response further upstream by limiting MMP secretion so chemokines and cytokines available which leads to the further suppression of cytokines. A reduction in pro-inflammmatory cytokines promotes survival of periodontal pathogens that encourage disease progression. Therefore, a decrease in secretion of matrix metalloproteinase by a primary monocyte exposed to nicotine could further inhibit the inflammatory response by restricting chemotaxis. In conclusion, the novel finding of nicotine altering the secretion of matrix metalloproteinase will add to current research and be an addition to future research.

Limitations on the proposed model could be that LPS E. coli is a bacteria pathogen that is not specifically found in large amounts in the periodontal tissues. When applying the model to periodontal disease it may be applicable to involve periodontal pathogens.

Further research pursuits include characterizing the $\alpha 7 \mathrm{nAChR}$ receptor pathway and the TLR pathway role in suppression of matrix metalloproteinase 9 secretion. Studies have shown other important signaling molecules down stream to both receptors. (Wang 2014) These signaling molecules could help to find a more specific control than the cholinergic anti-inflammatory pathway that nictone is engaging which then could be used as a therapeutic target. Other studies that show promise involve characterzing more of the matrix metalloprotienases (there are approximately 20 matrix metalloproteinases) that are 
involve with the LPS-induced cholinergic inhibition by nicotine. Further matrix metalloproteinase study would bring further insight into periodontal disease because periodontal disease usually involves a complex amount of matrix metalloproteinase. The model used human monocytes to exhibit the cholinergic inhibition of LPS induction it would further aid the research body of knowledge to observe other immune cells such as neutrophils. Neutrophils would be of interest because they are more abundant than monocytes and are usually first responders to pathogen insults. Neutrophils have a unique role in periodontal disease so applying the model to neutrophils would be insightful. Finally looking at the activity of matrix metalloprotienases would be intuitive. It has been recently shown that a reduction in matrix metalloprotienases activity significantly reduces intravascular accumulation and transmigration of immune cells. (Lerchenberger et al 2013) Further studies that show a reduction in chemotaxis of immune cells or a reduction in extracellular matrix breakdown by immune cells when exposed to nicotine would further research because nicotine has been associated with a reduction in immunity response. Overall, this model was established to further to assess if matrix metalloproteinase 9 was effected by the cholinergic inhibition of the anti-inflammatory pathway by nicotine when immune cells are exposed to LPS and to bring insight to nicotines role in disease susceptibility. 


\section{REFERENCES}

Ambrose, J. A., \& Barua, R. S. (2004). The pathophysiology of cigarette smoking and cardiovascular disease: an update. J Am Coll Cardiol, 43(10), 1731-1737. doi: 10.1016/j.jacc.2003.12.047

Arias, H. R., Richards, V. E., Ng, D., Ghafoori, M. E., Le, V., \& Mousa, S. A. (2009). Role of non-neuronal nicotinic acetylcholine receptors in angiogenesis. Int J Biochem Cell Biol, 41(7), 1441-1451. doi: 10.1016/j.biocel.2009.01.013

Bagaitkar, J., Demuth, D. R., \& Scott, D. A. (2008). Tobacco use increases susceptibility to bacterial infection. Tob Induc Dis, 4, 12. doi: 10.1186/1617-9625-4-12

Bagaitkar, J., Zeller, I., Renaud, D. E., \& Scott, D. A. (2012). Cotinine inhibits the proinflammatory response initiated by multiple cell surface Toll-like receptors in monocytic THP cells. Tob Induc Dis, 10(1), 18. doi: 10.1186/1617-9625-10-18

Barua, R. S., Ambrose, J. A., Eales-Reynolds, L. J., DeVoe, M. C., Zervas, J. G., \& Saha, D. C. (2001). Dysfunctional endothelial nitric oxide biosynthesis in healthy smokers with impaired endothelium-dependent vasodilatation. Circulation, 104(16), 1905-1910.

Berezow, A. B., Ernst, R. K., Coats, S. R., Braham, P. H., Karimi-Naser, L. M., \& Darveau, R. P. (2009). The structurally similar, penta-acylated lipopolysaccharides of Porphyromonas gingivalis and Bacteroides elicit strikingly different innate immune responses. Microb Pathog, 47(2), 68-77. doi: 10.1016/j.micpath.2009.04.015

Bondy-Carey, J. L., Galicia, J., Bagaitkar, J., Potempa, J. S., Potempa, B., Kinane, D. F., . . Scott, D. A. (2013). Neutrophils alter epithelial response to Porphyromonas gingivalis in a gingival crevice model. Mol Oral Microbiol, 28(2), 102-113. doi: 10.1111/omi.12008

Borojevic, T. (2012). Smoking and periodontal disease. Mater Sociomed, 24(4), 274-276. doi: $10.5455 / \mathrm{msm} .2012 .24 .274-276$

Brinckerhoff, C. E., \& Matrisian, L. M. (2002). Matrix metalloproteinases: a tail of a frog that became a prince. Nat Rev Mol Cell Biol, 3(3), 207-214. doi: 10.1038/nrm763 
Buduneli, N., Larsson, L., Biyikoglu, B., Renaud, D. E., Bagaitkar, J., \& Scott, D. A. (2011). Fatty acid profiles in smokers with chronic periodontitis. J Dent Res, 90(1), 47-52. doi: 10.1177/0022034510380695

de Jonge, W. J., \& Ulloa, L. (2007). The alpha7 nicotinic acetylcholine receptor as a pharmacological target for inflammation. Br J Pharmacol, 151(7), 915-929. doi: 10.1038/sj.bjp.0707264

Galis, Z. S., Johnson, C., Godin, D., Magid, R., Shipley, J. M., Senior, R. M., \& Ivan, E. (2002). Targeted disruption of the matrix metalloproteinase-9 gene impairs smooth muscle cell migration and geometrical arterial remodeling. Circ Res, 91(9), 852-859.

Highfield, J. (2009). Diagnosis and classification of periodontal disease. Aust Dent J, 54 Suppl 1, S11-26. doi: 10.1111/j.1834-7819.2009.01140.x

Holladay, M. W., Dart, M. J., \& Lynch, J. K. (1997). Neuronal nicotinic acetylcholine receptors as targets for drug discovery. J Med Chem, 40(26), 4169-4194. doi: $10.1021 / \mathrm{jm} 970377 \mathrm{o}$

Holt, S. C., \& Ebersole, J. L. (2005). Porphyromonas gingivalis, Treponema denticola, and Tannerella forsythia: the "red complex", a prototype polybacterial pathogenic consortium in periodontitis. Periodontol 2000, 38, 72-122. doi: 10.1111/j.16000757.2005.00113.x

Hosey, M. M. (1992). Diversity of structure, signaling and regulation within the family of muscarinic cholinergic receptors. FASEB J, 6(3), 845-852.

Johnson, G. K., \& Guthmiller, J. M. (2007). The impact of cigarette smoking on periodontal disease and treatment. Periodontol 2000, 44, 178-194. doi: 10.1111/j.1600-0757.2007.00212.x

Keles, G. C., Gunes, S., Sumer, A. P., Sumer, M., Kara, N., Bagci, H., \& Koprulu, H. (2006). Association of matrix metalloproteinase-9 promoter gene polymorphism with chronic periodontitis. J Periodontol, 77(9), 1510-1514. doi: 10.1902/jop.2006.050378

Kim, T. H., Kim, S. J., \& Lee, S. M. (2014). Stimulation of the alpha7 nicotinic acetylcholine receptor protects against sepsis by inhibiting Toll-like receptor via phosphoinositide 3-kinase activation. J Infect Dis, 209(10), 1668-1677. doi: 10.1093/infdis/jit669

Kugiyama, K., Yasue, H., Ohgushi, M., Motoyama, T., Kawano, H., Inobe, Y., . . Sugiyama, S. (1996). Deficiency in nitric oxide bioactivity in epicardial coronary arteries of cigarette smokers. J Am Coll Cardiol, 28(5), 1161-1167. doi: 10.1016/S0735-1097(96)00325-7 
Lerchenberger, M., Uhl, B., Stark, K., Zuchtriegel, G., Eckart, A., Miller, M., . . . Reichel, C. A. (2013). Matrix metalloproteinases modulate ameboid-like migration of neutrophils through inflamed interstitial tissue. Blood, 122(5), 770780. doi: 10.1182/blood-2012-12-472944

Loffek, S., Schilling, O., \& Franzke, C. W. (2011). Series "matrix metalloproteinases in lung health and disease": Biological role of matrix metalloproteinases: a critical balance. Eur Respir J, 38(1), 191-208. doi: 10.1183/09031936.00146510

Loo, W. T., Wang, M., Jin, L. J., Cheung, M. N., \& Li, G. R. (2011). Association of matrix metalloproteinase (MMP-1, MMP-3 and MMP-9) and cyclooxygenase-2 gene polymorphisms and their proteins with chronic periodontitis. Arch Oral Biol, 56(10), 1081-1090. doi: 10.1016/j.archoralbio.2011.03.011

Matthay, M. A., \& Ware, L. B. (2004). Can nicotine treat sepsis? Nat Med, 10(11), 1161 1162. doi: $10.1038 / \mathrm{nm} 1104-1161$

McCrea, K. A., Ensor, J. E., Nall, K., Bleecker, E. R., \& Hasday, J. D. (1994). Altered cytokine regulation in the lungs of cigarette smokers. Am J Respir Crit Care Med, 150(3), 696-703. doi: 10.1164/ajrccm.150.3.8087340

McQuibban, G. A., Gong, J. H., Wong, J. P., Wallace, J. L., Clark-Lewis, I., \& Overall, C. M. (2002). Matrix metalloproteinase processing of monocyte chemoattractant proteins generates $\mathrm{CC}$ chemokine receptor antagonists with anti-inflammatory properties in vivo. Blood, 100(4), 1160-1167.

Ogawa, T., Asai, Y., Makimura, Y., \& Tamai, R. (2007). Chemical structure and immunobiological activity of Porphyromonas gingivalis lipid A. Front Biosci, 12, 3795-3812.

Page-McCaw, A., Ewald, A. J., \& Werb, Z. (2007). Matrix metalloproteinases and the regulation of tissue remodelling. Nat Rev Mol Cell Biol, 8(3), 221-233. doi: $10.1038 / \mathrm{nrm} 2125$

Palmer, R. M., Wilson, R. F., Hasan, A. S., \& Scott, D. A. (2005). Mechanisms of action of environmental factors--tobacco smoking. J Clin Periodontol, 32 Suppl 6, 180195. doi: 10.1111/j.1600-051X.2005.00786.x

Pihlstrom, B. L., Michalowicz, B. S., \& Johnson, N. W. (2005). Periodontal diseases. Lancet, 366(9499), 1809-1820. doi: 10.1016/S0140-6736(05)67728-8

Rehani, K., Scott, D. A., Renaud, D., Hamza, H., Williams, L. R., Wang, H., \& Martin, M. (2008). Cotinine-induced convergence of the cholinergic and PI3 kinasedependent anti-inflammatory pathways in innate immune cells. Biochim Biophys Acta, 1783(3), 375-382. doi: 10.1016/j.bbamcr.2007.12.003 
Scott, D. A., \& Martin, M. (2006). Exploitation of the nicotinic anti-inflammatory pathway for the treatment of epithelial inflammatory diseases. World $J$ Gastroenterol, 12(46), 7451-7459.

Scott, D. A., \& Singer, D. L. (2004). Suppression of overt gingival inflammation in tobacco smokers - clinical and mechanistic considerations. Int J Dent Hyg, 2(3), 104-110. doi: 10.1111/j.1601-5037.2004.00079.x

Smith, L. A., Paszkiewicz, G. M., Hutson, A. D., \& Pauly, J. L. (2010). Inflammatory response of lung macrophages and epithelial cells to tobacco smoke: a literature review of ex vivo investigations. Immunol Res, 46(1-3), 94-126. doi: $10.1007 / \mathrm{s} 12026-009-8133-6$

Sopori, M. (2002). Effects of cigarette smoke on the immune system. Nat Rev Immunol, 2(5), 372-377. doi: 10.1038/nri803

Storr, C. L., Zhou, H., Liang, K. Y., \& Anthony, J. C. (2004). Empirically derived latent classes of tobacco dependence syndromes observed in recent-onset tobacco smokers: epidemiological evidence from a national probability sample survey. Nicotine Tob Res, 6(3), 533-545. doi: 10.1080/14622200410001696493

United States. Public Health Service. Office of the Surgeon General. (2010). How tobacco smoke causes disease : the biology and behavioral basis for smokingattributable disease : a report of the Surgeon General. Rockville, MD

Washington, DC: U.S. Dept. of Health and Human Services, Public Health Service

For sale by the Supt. of Docs., U.S. G.P.O.

van Winkelhoff, A. J., Bosch-Tijhof, C. J., Winkel, E. G., \& van der Reijden, W. A. (2001). Smoking affects the subgingival microflora in periodontitis. $J$ Periodontol, 72(5), 666-671. doi: 10.1902/jop.2001.72.5.666

Wang, H., Brown, J., Gao, S., Liang, S., Jotwani, R., Zhou, H., . . Lamont, R. J. (2013). The role of JAK-3 in regulating TLR-mediated inflammatory cytokine production in innate immune cells. J Immunol, 191(3), 1164-1174. doi: 10.4049/jimmunol.1203084

Wang, X. L., \& Scott, D. A. (2005). Molecular mechanisms of tobacco-induced diseases. Hauppauge, N.Y.: Nova Biomedical Books.

Xu, M., Scott, J. E., Liu, K. Z., Bishop, H. R., Renaud, D. E., Palmer, R. M., . . Scott, D. A. (2008). The influence of nicotine on granulocytic differentiation - inhibition of the oxidative burst and bacterial killing and increased matrix metalloproteinase- 9 release. BMC Cell Biol, 9, 19. doi: 10.1186/1471-2121-9-19 
Yamamoto, T., Kodama, T., Lee, J., Utsunomiya, N., Hayashi, S., Sakamoto, H., . . . Kadowaki, M. (2014). Anti-allergic role of cholinergic neuronal pathway via alpha7 nicotinic ACh receptors on mucosal mast cells in a murine food allergy model. PLoS One, 9(1), e85888. doi: 10.1371/journal.pone.0085888 


\section{CURRICULUM VITAE}

\section{Harrison Miles Black}

Birthday:

Citizenship:

Address:

Contact Information:

\section{Higher Education}

2006-2010

2010-current

2012-current
April 9 ${ }^{\text {th }}, 1988$

U.S.A.

Home: 723 E. Madison Louisville KY 40202

Cell: (316) 393-6499

ahrris0n@gmail.com

Truman State University

Kirksville, MO

B.S. Chemistry

University of Louisville School of Dentistry Louisville, Kentucky

D.M.D. (Dentistry)

University of Louisville School of Dentistry Louisville, Kentucky

M.S. (Oral Biology)

\section{Honors and Academic Achievements}

2013

2012-2013

2013

2012

2012

2011
Kentucky Clinical Outreach Scholarship

ULSD Admissions Committee-Student Member

Student National Dental Association National Corporate

Roundtable Representative

SNDA National Medium Chapter of the Year- President

Colgate Foundation Scholarship Kentucky Dental Society

National Health Service Corps Scholarship Recipient 
2011

2010-2011

2010-2011

\section{Academic Positions}

2010-current

2011-2013

2011-2013

2011-2013

2011-2012

2009-2010

Work Experiences

2013

\section{Community Service}

2013

2013

2013

2013

2013

2011-2013

2011-2013

2011-2013
American Dental Association Minority Scholarship Recipient

University of Louisville School of Dentistry Dean's List

General Dentistry Scholarship (Full Tuition)
American Student Dental Association- General Member

Hispanic Dental Association Student Chapter- Member

Student National Dental Association- President

Cultural Competency Committee- Member

American Dental Association Student Ambassador Program

Alpha Phi Alpha Fraternity Inc., President

Dental Student (AHEC Externship)

Park Duvalle Community Health Clinic

Louisville Ky, 40217

Back to School Health Screenings at Lincoln Elementary

Back to School Health Screenings at Baxter Community Center

Oral Cancer Screenings at the Kentucky State Fair

Remote Area Medical (Greenup Co., KY) Volunteer

Remote Area Medical (Harlan, KY) Volunteer

SNDA University of Louisville Oral Cancer Walk-Director

University of Louisville School of Dentistry Impressions

Program- Director

SNDA Canned Food Drive-Director 
2011-2013

Project G.A.M.E. Whitney Young Foundation

2011-2013

Beat the Pumpkin Volunteer

2010

Sojourn Church Health Fair

Research Experiences:

2013

2012-2013

2012-2013

2012

2011-2013

2011
SNDA National Research Competition $2^{\text {nd }}$ place

NCI Cancer Education Program

University of Toxicology and Pharmacology

University of Louisville School of Dentistry

SNDA National Research Competition Participant

James Brown Cancer Center Retreat

Research Louisville Participant

Summer Research Student

University of Louisville School of Dentistry 